\title{
Menerapkan Konsep Pelayan Tuhan Perjanjian Baru pada Masa Kini
}

Asih Rachmani Endang Sumiwi ${ }^{1}$, Joseph Christ Santo ${ }^{2}$

1,2Sekolah Tinggi Teologi Berita Hidup, Surakarta, Indonesia

1asihres@gmail.com,2jx.santo@gmail.com

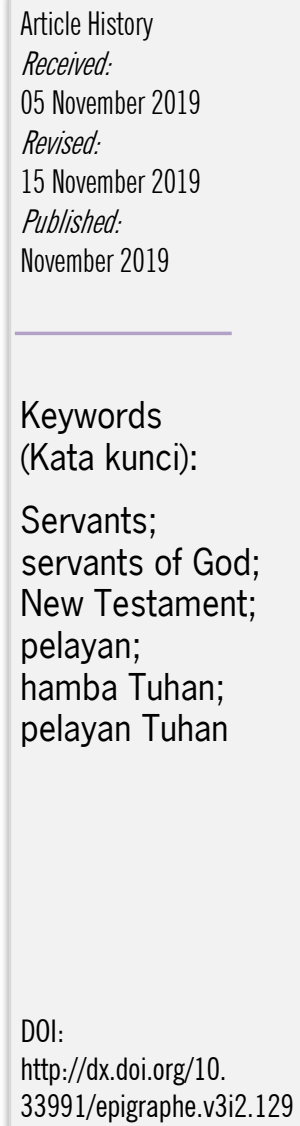

\section{Pendahuluan}

Ketika istilah pelayan Tuhan disebut, maka yang muncul dalam pemikiran sebagian orang Kristen adalah orang yang terlibat aktif di lingkungan gereja, yaitu orang yang terlibat dalam kegiatan liturgi, diakonia, pastoral dan misi. Pada umumnya yang dimengerti sebagai aktivitas seorang pelayan Tuhan adalah melakukan pekerjaan gerejawi, seperti berkhotbah, memimpin puji-pujian, mengajar sekolah minggu, mengorganisasi kegiatan pemuda remaja, bermain musik dan aktivitas lain yang ada di lingkungan gereja atau yang juga sering disebut sebagai kegiatan rohani. ${ }^{1}$

\begin{abstract}
The term "servant of God" has a growing meaning, and at this time the phrase has several meanings. In its development there is also the meaning of "servant of God" which shifts from the original understanding. This can cause inconsistencies in the function of God's servant in the congregation. With word studies, this research tries to reformulate the concept of servant of God based on the use of some words about servants in the books of the New Testament. The use of these words in the cultural context at that time showed the characteristics of "servants", and from those characteristics it could be formulated the concept of servants of the Lord's New Testament. The results of this study indicated several criteria that must be owned by a member of the congregation so that he deserves to be set as a servant of God.

Abstrak juga makna "pelayan Tuhan" yang bergeser dari pengertian semula. Hal Denga menimbulkan inkonsistensi fungsi pelayan Tuhan dalam jemaat. pelayan Tuha berda dalam kitab-kitab Perjanjian Baru. Penggunaan kata-kata tersebut dalam konteks budaya pada waktu itu menunjukkan karakteristik "pelayan", dan dari karakterisik itu dapat dirumuskan konsep pelayan Tuhan Perjanjian Baru. Hasil dari penelitian ini menunjukkan beberapa kriteria yang perlu dimiliki seorang warga jemaat agar ia layak ditetapkan sebagai pelayan Tuhan.
\end{abstract}


Berkembangnya konsep tersebut mendorong beberapa orang memperlengkapi diri dengan belajar tentang dasar dan teknik pelayanan berkenaan dengan kegiatan gereja tersebut. Memang dengan pembekalan melalui pelajaran-pelajaran tersebut diharapkan kualitas pelayanan menjadi lebih baik. Namun di antara orang yang berupaya memperlengkapi diri itu, ada yang memiliki motivasi yang kurang tepat, yaitu yang berpikir bahwa dengan berbekal hal-hal yang dipelajarinya itu mereka merasa layak disebut sebagai pelayan Tuhan. Dengan kata lain, ada pemikiran bahwa yang disebut pelayan Tuhan adalah orang-orang yang sudah memiliki pengetahuan rohani dan dibekali dengan pelajaran-pelajaran tertentu.

Pada faktanya ada beragam pemahaman tentang arti pelayan Tuhan. Ada yang menganggap hanya orang yang disahkan oleh Sinode atau Gembala Sidang yang dapat diakui sebagai pelayan Tuhan. Contoh, ketika seseorang dilantik dengan jabatan kependetaan, dirinya resmi disebut pelayan Tuhan (hamba Tuhan) secara organisasi, dan ia mendapatkan kedudukan yang berbeda dari jemaat biasa. Demikian juga ketika seseorang ditetapkan untuk terlibat bidang pelayanan tertentu dalam gereja lokal, dirinya dirujuk menduduki status sebagai pelayan Tuhan pada gereja lokal tersebut.

Ditemukan juga fakta yang menunjukkan bahwa seorang pelayan Tuhan memiliki kriteria yang sangat kontras dari kata "pelayan"itu sendiri sebagaimana dijelaskan pada paragraf sebelumnya. Ada pelayan Tuhan yang menuntut fasilitas ketika ia melakukan aktivitas yang berhubungan dengan ibadah, misalnya meminta penjemputan dengan mobil merek tertentu. Pelayan Tuhan yang lain meminta tas dan perlengkapannya dibawakan. Bahkan ada pelayan Tuhan yang tidak malu menyebutkan nominal tertentu sebagai imbalan dari pelayanannya. ${ }^{2}$

Fakta berikutnya yang ditemukan adalah kelonggaran dalam menetapkan kriteria pelayan Tuhan. Beberapa gereja atau lembaga pelayanan menetapkan standar yang rendah dalam melibatkan seseorang menjadi pelayan Tuhan. Dalam standar longar ini terlihat adanya pelayan Tuhan yang diizinkan melayani pekerjaan Tuhan padahal belum memiliki pertobatan yang sungguh atau hidupnya masih terikat dengah dosa, sehingga dalam pelayanannya tidak menunjukkan karakter yang memuliakan Tuhan. Berdasarkan fakta-takta tersebut di atas, muncul beberapa pertanyaan. Pertama bagai-mana konsep Pelayan Tuhan yang ideal menurut Alkitab, dalam hal ini Perjanjian Baru. Dan kedua, bagaimana konsep tersebut diimplementasikan di masa kini di tengah zaman yang telah berubah?

\section{Metode}

Penelitian ini merupakan penelitian kualitatif yang menggunakan metode deskriptif analisi. ${ }^{3}$ Prinsip-prinsip hermeneutika digunakan dalam studi kata tentang pelayan Tuhan. Peneliti mengumpulkan kata-kata dalam Perjanjian Baru yang memiliki arti

\footnotetext{
${ }^{2}$ Ferry Napitupulu, "Uang Terima Kasih Dipatok Pendeta," Kompasiana, Desember 23, 2011, https://www.kompasiana.com/silversteven/550ble28813311e8a8/uang-terima-kasih-dipatok-pendeta

${ }^{3}$ Sally Sieloff Magnan and John W. Creswell, "Research Design: Qualitative and Quantitative Approaches," The Modern Language Journal 81, no. 2 (2006): 256.
} 
pelayan atau berhubungan dengan pelayan. Perjanjian Baru yang dimaksud dalam tulisan ini adalah kitab-kitab dari Matius sampai Wahyu, sehingga konsep pelayan Tuhan Perjanjian Baru dirumuskan berdasarkan narasi yang tertulis dalam kitab-kitab Perjanjian Baru. Data-data yang ditemukan tersebut diinvertarisasi baik maknanya maupun konteksnya. Setelah terumuskan konsep pelayan Tuhan Perjanjian Baru, kemudian dikembangkan penerapannya untuk masa kini.

Dengan mengunakan alat bantu konkordansi dapat ditemukan ayat-ayat yang memuat kata-kata tersebut. Setiap kata yang berhubungan dengan pelayan dapat ditelusuri pada bahasa asli Perjanjian Baru. Sangat dimungkinkan terdapat lebih dari satu kata yang dapat digunakan untuk merujuk pada konsep pelayan. Kemudian peneliti menelusuri konteks pemakaian kata-kata tersebut pada masa Alkitab ditulis. Selain makna literal yang ditemukan pada kamus, setiap kata yang digunakan mengandung makna yang khas pada konteksnya. Dari makna literal maupun makna kontekstual, maka dapat susun kriteria-kriteria pelayan Tuhan yang alkitabiah.Rujukan lain dari tinjauan literatur ikut dipergunakan di dalam mendukung analisis. ${ }^{4}$

\section{Pembahasan}

\section{Arti Pelayan}

Dalam bahasa asli Perjanjian Baru ada beberapa kata yang memiliki makna pelayan. Kata-kata tersebut adalah doulos, huperetes, diakonos, oiketes, therapon, dan leitourgos. Ada kata misthios dan misthotos, namun kurang tepat dipakai dalam konteks pelayan Tuhan, karena kedua kata tersebut lebih tepat diterjemahkan "orang upahan". Ada juga kata paidiske dan pais, namun kedua kata ini lebih berhubungan dengan pengasuh anak-anak, dan jarang dikaitkan dengan pelayan Tuhan. Dengan menelusuri makna dan penggunaan kata-kata tersebut dalam konteks para rasul dan gereja mulamula, maka dapat ditemukan kriteria-kriteria bagaimana seharusnya seseorang melayani Tuhan yang Alkitabiah. ${ }^{5}$

\section{Doulos}

Kata doulos memiliki bentuk dasar doulos yang artinya budak atau hamba. Beberapa turunan dari doulos adalah sundoulos (sesama budak), doulē (budak perempuan), douleuō (menjadi budak), douleia (perbudakan), douloō (memperbudak), katadoulō̄ (memperbudak), doulagōgeō (memperbudak), ophthalmodoulia (mata-layanan). ${ }^{6}$ Semua kata-kata ini ada hubungannya dengan perbudakan. Ketika kata doulos atau turunannya dipergunakan, ini merujuk kepada ketergantungan seorang budak kepada

\footnotetext{
${ }^{4}$ Joy Don Baker, "The Purpose, Process, and Methods of Writing a Literature Review," AORN Journal 103, no. 3 (2016): 265-269.

${ }^{5}$ Sonny Zaluchu, "Respons Tests of Leadership Menurut Teori Frank Damazio Pada Mahasiswa Pascasarjana Jurusan Kepemimpinan Kristen STT Harvest Semarang,” Jurnal Jaffray 16, no. 2 (2018): 145-160, https://ojs.sttjaffray.ac.id/index.php/JJV71/article/view/289.

${ }^{6}$ Gerhard Kittel, Gerhard Friedrich and Geoffrey William Bromiley, Theological Dictionary of the New Testament, Translation of: Theologisches Worterbuch Zum Neuen Testament. (Grand Rapids, Mich.: W.B. Eerdmans, 1995, c1985), 182.
} 
tuan. Doulos juga mengandung arti komitmen total kepada tuannya dan tidak bisa mengabdi kepada dua tuan. ${ }^{7}$

Pada zaman Perjanjian Baru, seorang budak dapat dibeli atau dijual sebagai komoditas. Seumur hidupnya ia adalah milik tuannya, entah tuannya baik atau bengis, demikian nasib seorang budak seumur hidupnya. Ia bisa lepas dari tuannya jika ia memiliki cukup uang untuk menebus dirinya, tetapi ini mustahil. Seorang budak adalah seorang yang sama sekali tidak memiliki kepentingan diri sendiri. Dengan ketaatan penuh dan kerendahan hati ia hanya bisa berkata dan bertindak atas nama tuannya. Dalam hal ini tuannya berbicara dan bertindak melalui dia. Seorang doulos benar-benar tak berdaya.

Yesus Kristus menempatkan diri sebagai doulos. Ketika membasuh kaki muridmurid-Nya, Ia menunjukkan bahwa itu adalah jabatannya, juga untuk menunjukkan bahwa keberadaan-Nya adalah untuk melayani, bukan untuk mencari kekuasaan atau kemuliaan, karena mencuci kaki adalah tugas yang berat (Yoh. 13: 1 dst.). Tentu saja Yesus juga menunjukkan apa yang akan menjadi titik kehidupan para murid sendiri sebagai rasul-rasulnya, karena doulos tidak lebih besar daripada kurios-nya (tuannya), atau apostolos tidak lebih besar daripada yang mengirimnya (Yoh. 13:16). Paulus memberikan aplikasi yang lebih umum dari pelajaran ini ketika ia mengatakan kepada jemaat Galatia, bahwa karena mereka dipanggil untuk kebebasan, mereka harus melayani (douleuein) satu sama lain dalam kasih (Gal. 5:13). ${ }^{8}$

Budaya Yunani dan Yudaisme cenderung menempatkan status budak pada sosial dan etis yang lebih rendah, menempatkan budak sepenuhnya di bawah kendali tuan mereka, dan menganggap istilah "budak" sebagai penghinaan yang mematikan. ${ }^{9}$ Dalam Filipi 2:7 Yesus dikatakan mengambil bentuk doulos yang melambangkan titik terendah dalam jalan kenosis Yesus. Yesus sebagai doulos melibatkan situasi baru yang sangat berbeda dari situasi sebelumnya, dan dalam situasi ini Ia tunduk pada kematian salib.

\section{Huperetes}

Istilah huperetes pertama kali muncul dengan merujuk pada Hermes, utusan para dewa. Ini menunjukkan seseorang yang melakukan kehendak Zeus dan memiliki otoritas di belakangnya. Dalam hal hubungan antara Hermes dan Zeus ini huperetes memiliki arti asisten. ${ }^{10}$ Secara etimologis, kata huperetes terbentuk dari kata hupo yang berarti "bawah", dan eretes yang berarti "pendayung". Namun demikian arti kata majemuk huperetes tidak dapat diturunkan serta merta dari dua kata yang membentuknya, karena gabungan dua kata ini telah membentuk arti baru. Arti dari huperetes adalah asisten, bawahan, kelasi, pengawal, ajudan. Dalam arti asisten, huperetes menunjukkan

\footnotetext{
${ }^{7}$ Frank Damazio, The Making of A Leader (Portland: City Bible Publishing, 1988), 171-186.

${ }^{8}$ Yahya Wijaya, "Kepemimpinan Yesus Sebagai Acuan Bagi Kepemimpinan Gereja Masa Kini," Jurnal Jaffray 16, no. 2 (2018): 129.

${ }^{9}$ Ibid hal 183

${ }^{10}$ Gerhard Kittel, Gerhard Friedrich and Geoffrey William Bromiley, Theological Dictionary of the New Testament, Translation of: Theologisches Worterbuch Zum Neuen Testament. (Grand Rapids, Mich.: W.B. Eerdmans, 1995, c1985), 1231.
} 
seseorang yang membantu mengamankan sesuatu untuk orang lain, sehingga orang yang dibantu itu lebih lancar dalam melakukan aktivitasnya.

Dalam arti bawahan, melayani sebagai huperetes artinya melayani sebagai bawahan terhadap atasannya. Seorang huperetes adalah seorang yang segera memberikan tanggapan dan tidak banyak bertanya tentang tugas yang dipercayakan kepadanya. Ia tidak perlu mengetahui mengapa atasannya memerintahkan suatu tugas untuk dikerjakannya. Kadang-kadang seorang huperetes diperhadapkan kepada tindakan yang tidak masuk dalam nalarnya untuk dikerjakan, tetapi yang diutamakan dari seorang huperetes adalah kepatuhan kepada atasan yang menyuruhnya.

Dalam bidang pelayaran ia adalah seorang kelasi kapal, ia tidak perlu banyak bertanya ke mana kapten kapal akan mengarahkan kapal; yang penting baginya adalah melakukan tugasnya. Ketika ia diperintahkan nakhoda untuk mendayung, yang dilakukannya adalah mendayung; ketika diperintahkan untuk memutar haluan; ia harus memutar haluan; ketika diperintahkan untuk menurunkan jangkar, jangkar harus diturunkan. Peran huperetes sebagai kelasi hampir sama dengan sebagai bawahan, ia tidak perlu terlalu ingin tahu apa tujuan dari orang yang memberi perintah kepadanya.

Sebagai pengawal atau ajudan, ia adalah orang yang siap menolong agar aktivitas tuannya lancar. Ia selalu berada dekat dengan tuannya untuk menerima perintah yang diterima kapan saja, bahkan secara mendadak. Sebagai orang yang selalu berada dekat dengan tuannya, kadang-kadang ia mendengar pembicaraan tuannya, termasuk juga mungkin pembicaraan yang bersifat rahasia atau menyangkut rencana-rencana tuannya. Namun kalaupun sampai ia mengetahui rahasia itu ia harus menyimpannya dan tidak boleh membocorkannya. Kesetiaan kepada tuannya ditunjukkan dengan keberadaannya yang selalu dekat dengan tuannya dan memperhatikan apa yang sedang dan akan dikerjakan tuannya.

Paulus menempatkan dirinya sebagai huperetes (1 Kor. 4:1) bagi Kristus. Artinya ia siap untuk melakukan apa saja perintah Kristus. Kesiapsiagaan Paulus dalam menerima perintah ditunjukkan setiap kali ia melakukan perjalanan misi. Kitab Kisah Para Rasul mencatat bahwa perjalanan misi yang dilakukan Paulus bergantung pada perintah yang ia terima dari Tuhan. Dalam hal mendapatkan informasi yang bersifat rahasia, Paulus juga menempatkan diri sebagai huperetes, dan ia sanggup menjaga rahasia iman dengan baik. Dalam Kisah Para Rasul 20:34 sahabat-sahabat Paulus bertindak selaku huperetes bagi Paulus. Sahabat-sahabat Paulus menjadi penolong bagi Paulus agar pelayanannya menjadi lebih efektif. Fungsi huperetes di sini adalah sebagai asisten. ${ }^{11}$

${ }^{11}$ Sonny Zaluchu, “Analisis Kisah Para Rasul 15 Tentang Konflik Paulus Dan Barnabas Serta Kaitannya Dengan Perpecahan Gereja," Kurios 4, no. 2 (2018): 107-117, http://www.sttpb.ac.id/ejournal/index.php/kurios; Bob Jokiman, "Dasar-Dasar Alkitabiah Pengembangan Kepemimpinan," Veritas : Jurnal Teologi dan Pelayanan 4, no. 1 (2018): 87-106. 


\section{Diakonos}

Arti utama diakonos adalah pelayan meja atau pelayan di meja makan. ${ }^{12}$ Tugasnya adalah menantikan perintah di sekitar meja makan (Mat. 8:15; Ef. 4:12). Ini bukan pekerjaan yang menyenangkan, karena seringkali ia akan menerima dampratan dari orang yang merasa kurang puas dilayani. Dalam perjamuan perkawinan di Kana disebutkan peran pada diakonos dalam menjalankan perintah Yesus (Yoh. 2:5,9). Ketaatan mereka melakukan perintah Yesus tampak dalam tindakan mereka mencedok air dan membawa kepada pemimpin pesta, sekalipun hal itu aneh dan berisiko.

Kata diakonos juga berarti pelayan dari seorang tuan. Matius 22:13 dan Yohanes 12:26 mengindikasikan keberadaan orang-orang Kristen sebagai pelayan Kristus. Dalam arti luas kata ini menyatakan seseorang yang memperhatikan kebutuhan sesama, kemudian berupaya untuk dapat menolong memenuhi kebutuhan itu. Beberapa teks dalam Alkitab menyebutkan fungsi diakonos dalam hal melayani sesama (Mrk. 9:35; Mat. 20:26; 23:11). Orang bisa saja bekerja sebagai budak (doulos) dan tidak menolong seorangpun; tetapi jika ia seorang diakonos, ia berkaitan erat dengan upaya menolong orang lain (Luk. 22:27; Yoh. 12:26; 1 Tim. 3:13).

Di dalam Lukas 22:27 Kristus menempatkan diri di tengah-tengah murid-Nya sebagai ho diakonon, yang melayani mereka yang duduk makan. Perkataan Yesus ini memberikan penjelasan bahwa orang-orang yang dilayani di meja makan lebih besar daripada diakonos yang melayani. ${ }^{13}$ Dalam perkembangannya istilah diakonos digunakan untuk pelayan-pelayan yang membantu tugas penggembalaan. Istilah ini pertama kali digunakan dalam Kisah 6 ketika para rasul memerlukan

\section{Oiketes}

Kata oiketes berarti pelayan rumah (Luk. 16:13; Kis. 10:7; Rm. 14:4; 1Ptr. 2:18). ${ }^{14}$ Kata ini berhubungan dengan oikos yang berarti rumah, jadi oiketes adalah seorang yang melayani di sebuah rumah. Ia menantikan perintah dari tuannya sehubungan dengan urusan-urusan pengaturan rumah. Dari seorang oiketes dibutuhkan adanya kesetiaan dan tanggung jawab kepada rumah di mana ia mengabdi. Tuan rumah mengharapkan rumah di mana ia tinggal selalu dalam keadaan rapi dan tertata, dan di sinilah keberadaan oiketes dalam menolong tuannya menyelesaikan urusan rumah sebagaimana keinginan tuannya.

Jika gereja dipandang sebagai rumah Allah, maka melayani sebagai seorang oiketes dapat diartikan melayani pada rumah Allah. Sebagai seorang oiketes, pelayan Tuhan perlu memiliki hati agar gereja tertata dengan baik, dan segala urusan di dalam rumah

\footnotetext{
${ }^{12}$ Gerhard Kittel, Geoffrey William Bromiley, and Gerhard Friedrich, Theological Dictionary of the New Testament (Grand Rapids, MI: Eerdmans, 1976).

${ }^{13}$ Ferry Pigai, "Analisis Ciri Kepemimpinan Hamba Serta Relevansinya Pada Masa Kini Berdasarkan Injil Matius 20:26-28 [Analysis of the Characteristics of Servant Leadership and Relevance Based on the Gospel of Matthew 20:26-28]," Jurnal Jaffray (2013).

${ }^{14}$ James Swanson, Dictionary of Biblical Languages With Semantic Domains : Greek (New Testament), ed. Inc. Logos Research Systems (Oak Harbor, 1997).
} 
Allah. Ia selalu siap menunggu arahan dari Kristus, pemilik rumah, untuk terwujudnya apa yang Ia kehendaki di rumah tersebut.

\section{Therapon}

Kata therapon berarti perawat rumah atau pengatur rumah. Kata ini berhubungan dengan therapeuo yang berarti merawat atau menyembuhkan. ${ }^{15}$ Seorang therapon bertanggung jawab agar apa yang dipercayakan kepadanya terawat dan terpelihara dengan baik. Alkitab menuliskan tentang Musa sebagai pelayan yang setia dalam segenap rumah Allah (Ibr. 3:5). Kata pelayan yang digunakan di sini adalah therapon. Musa menjadi kesaksian tentang pelayanan yang lebih kemudian, yaitu tentang Kristus yang setia melayani rumah-Nya, yaitu jemaat Tuhan.

\section{Leitourgos}

Kata leitourgos muncul lima kali dalam Perjanjian Baru. Kata ini seakar dengan leitourgia (pelayanan), leitourgeo (melayani), dan leitourgikos (pelayan).Kelompok kata ini umum digunakan dalam literatur Yunani tentang pelayanan yang diberikan kepada orang-orang sebagai entitas politik (secara etimologis berasal dari kata $\lambda$ ท́ï (leitos) yang berarti "mengenai orang-orang" dan हैpyov (ergon) yang berarti "pekerjaan" atau "pelayanan". 16

Leitourgos adalah orang yang melayani orang lain di depan publik (Kis. 13:2). Pelayanan ini dilakukan kepada sejumlah orang pada saat yang bersamaan. Dengan arti yang hampir sama dengan leitourgos, kata leitourgikos muncul hanya satu kali dalam Ibrani 1:14, merujuk kepada malaikat-malaikat sebagai roh-roh yang melayani. Objek dari pelayanan mereka adalah mereka yang harus memperoleh keselamatan. Karena seorang leitourgos harus berhadapan dengan banyak orang, maka ia perlu mempersiapkan diri sedemikian rupa agar dapat melayani dengan baik. Seorang leitourgos perlu terus merencanakan dan peningkatkan pelayanannya. Dalam perkembangannya istilah leitourgos dikenakan kepada orang-orang yang melayani di dalam ibadah, misalnya pemimpin ibadah. ${ }^{17}$ Dalam arti ini, pelayan Tuhan memiliki tangung jawab agar ibadah dapat terselenggara dengan baik, segala sesuatu perlu direncanakan dan dipersiapkan sedemikian rupa.

\section{Rangkuman Karakteristik Pelayan Tuhan}

Berdasarkan analisis beberapa kata yang memiliki arti "pelayan", dapat dirangkum beberapa karakteristik pelayan Tuhan sebagai berikut. Pelayan Tuhan adalah seorang hamba Kristus, yang sadar bahwa hidupnya adalah milik Kristus karena Kristus sudah menebus hidupnya. Ia memiliki komitmen kepada satu tuan, yaitu Kristus, dan tidak boleh mendua kepada tuan yang lain. Ia memiliki ketaatan penuh dan kerendahan hati.

\footnotetext{
${ }^{15}$ Horst Robert Balz and Gerhard Schneider, Exegetical Dictionary of the New Testament (Grand Rapids, MI: Eerdmans, 1993).

${ }^{16}$ Ibid.

${ }^{17}$ Jimmy Setiawan, "Menggagas Signifikansi Gestur Tubuh Dalam Ibadah Korporat Gereja Gereja Protestan [Initiating the Significance of Body Gesture in Corporate Protestant Church Worship]," Veritas 13, no. 1 (2012): 99-120, http://repository.seabs.ac.id/handle/123456789/264.
} 
Ia segera memberikan respons berupa tindakan dan tidak hanya berbicara tentang tugas yang dipercayakan kepadanya. Ia tidak selalu diperhitungkan, namun pelayanannya amat dibutuhkan, itu sebabnya seorang pelayan Tuhan tidak perlu mencari hormat atau peninggian bagi diri sendiri. Seorang pelayan Tuhan harus siap sedia dalam segala keadaan. Ia juga harus dapat menjaga rahasia. Ia selalu memperhatikan orang lain dalam memenuhi kebutuhannya. Ia memiliki kesetiaan dan tanggung jawab kepada rumah Tuhan. Ia memiliki kehidupan yang diamati banyak orang, karenanya ia harus hidup dalam integritas. Ia mempersiapkan diri agar dapat melayani ibadah dengan baik.

\section{Sikap dan Karakter yang Diharapkan dari Seorang Pelayan Tuhan}

\section{Menyadari hidupnya milik Kristus}

Karya penebusan Kristus adalah dasar bagi orang percaya untuk melayani-Nya. Orang percaya melayani Kristus bukan untuk mendapat perkenan-Nya melainkan karena Ia telah lebih dulu melayani. Karena itu seorang pelayan Tuhan harus yakin akan karya keselamatan Allah atas dirinya. Ia harus sadar bahwa hidupnya bukan miliknya lagi sebab telah ditebus menjadi milik Kristus. Kematian Kristus telah menebus orang percaya dari cara hidup yang sia-sia (1Ptr. 1:18-19). Oleh sebab itu seorang pelayan Tuhan harus berubah dari cara hidup yang lama yang dilakukannya di luar Kristus. Ia perlu mengalami pembaharuan pikiran, ${ }^{18}$ sehingga ia tidak lagi melakukan perbuatan sia-sia bukan karena terpaksa, melainkan karena telah mengerti kehendak Allah. ${ }^{19}$ Ia memiliki kesadaran untuk hidup dalam kebenaran karena mata hati yang telah diterangi. ${ }^{20}$

\section{Memiliki komitmen kepada satu tuan, yaitu Kristus}

Seorang pelayan Tuhan tidak boleh terikat pemberhalaan. Ia hanya mengabdi kepada Tuhan Yesus Kristus. Pemberhalaan pada masa kini dapat berbentuk okultisme, dan beberapa orang Kristen masih percaya pada okultisme bahkan ada yang masih melakukannya $^{21}$. Sebagai bentuk pengabdian tunggal kepada Tuhan Yesus Kristus, maka pelayan Tuhan harus meninggalkan okultisme. Okultisme dapat berupa perbuatan yang terang-terangan berhubungan dengan kuasa gelap seperti perdukunan dan spiritisme, namun ada juga yang sama-sama berbahaya namun perbuatan okultisme ini tidak terlalu terlihat, seperti percaya kepada ramalan dan takhayul. Seorang yang akan ditetapkan sebagai pelayan Tuhan perlu dilayani secara khusus apabila masih memiliki keterikatan dengan okultisme.

\footnotetext{
${ }^{18}$ Yotam Teddy Kusnandar, "Pentingnya Golden Character," Epigraphe 1, no. 1 (2017): 11-22.

${ }^{19}$ Asih Rachmani Endang Sumiwi, "Pembaharuan Pikiran Pengikut Kristus Menurut Roma 12:2," Jurnal Teologi Berita Hidup 1, no. 1 (2018).

${ }^{20}$ Joseph Christ Santo, "Makna Dan Penerapan Frasa Mata Hati Yang Diterangi Dalam Efesus 1: 18-19," Jurnal Teologi Berita Hidup 1, no. 2 (2018).

${ }^{21}$ Rahel Jum Juld and I Ketut Enoh, “Okultisme Dalam Pelayanan Pastoral,” Jurnal Jaffray 11, no. 2 (2013): 165 .
} 


\section{Memiliki ketaatan penuh dan kerendahan hati}

Seorang pelayan Tuhan adalah tidak mempertahankan kepentingan diri sendiri. Hidupnya hanya diperuntukkan bagi Tuhan. Di sinilah dibutuhkan penyangkalan diri seorang pelayan Tuhan. Tuhan menghendaki murid-murid-Nya rela melepaskan apa pun yang menjadi kesukaan dan kebanggaannya demi melakukan kehendak Tuhan. ${ }^{22}$ Ketaatan dan kerendahan hati diteladankan oleh Yesus dalam doa-Nya di taman Getsemani, "Bapa, biarlah cawan ini lalu daripada-Ku, tetapi bukan kehendak-Ku yang jadi tetapi kehendak-Mu." Ia rela melakukan dan menerima semua itu atas dasar kerelaan, dan hal ini menunjukkan kerendahan hati-Nya. ${ }^{23}$ Seperti halnya yang dilakukan oleh Yesus yang taat pada Allah Bapa yang mengutusnya. Begitupun para nabi dan rasul yang taat berbicara atas nama Allah. Seorang pelayan Tuhan yang menempatkan dirinya sebagai doulos maka dia memiliki ketaatan penuh kepada Tuhan.

Wujud dari ketaatan kepada Tuhan adalah ketaatan dalam melakukan firman-Nya. Pelayan Tuhan yang mempunyai ketaatan tanpa pamrih, menaati Firman Tuhan dan memenuhi rencana-Nya adalah kesukaan. Yang dimaksud ketaatan tanpa pamrih adalah ketaatan tanpa motivasi keuntungan, bukan ketaatan supaya menerima imbalan berkat dari Tuhan. Alkitab adalah firman Tuhan yang tertulis, maka seorang pelayan Tuhan yang taat akan melakukan apa yang ditulis dalam Alkitab tanpa mengharapkan keuntungan

\section{Memiliki respon yang baik atas tugas yang dipercayakan}

Dalam menjalankan tugas yang diberikan, seorang pelayan Tuhan harus memiliki respon yang baik, tidak perlu banyak bicara tetapi cakap mengerjakan apa yang menjadi bagiannya. Dalam pelayanan kadang-kadang muncul masalah yang disebabkan karena pelayan Tuhan yang terlalu banyak berbicara tetapi minim tindakan.

\section{Tidak mencari hormat bagi diri sendiri}

Sebagai hamba yang mengabdi kepada Kristus, seorang pelayan Tuhan tidak boleh mencari pujian dan penghormatan bagi dirinya sendiri. Dengan sadar seorang pelayan Tuhan mengembalikan segala pujian bagi Tuhan. Bahkan seandainya tidak seorang pun mengucapkan terima kasih untuk pelayanan yang telah dilakukannya, dengan berbesar hati ia dapat berkata, "Kami adalah hamba yang tidak berharga. Kami hanya melakukan apa yang wajib kami lakukan" (Luk. 17:10).

\section{Siap sedia dalam segala keadaan}

Sebagai seorang huperetes bagi Kristus, seorang pelayan Tuhan harus siap sedia dalam segala keadaan. Tentunya kesiapan yang dimaksud adalah sesuai dengan bidang pelayanannya. Memang ada pelayanan yang bersifat rutin, seperti pelayanan ibadah Minggu atau tengah minggu, tetapi ada pelayanan yang tidak bisa dijadwalkan, seperti

\footnotetext{
${ }^{22}$ Danny Yonathan, "Memahami Konsep Menyangkal Diri, Memikul Salib Dan Mengikut Yesus: Sebuah Analisis Biblikal Lukas 9:23-26," Jurnal Teologi Berita Hidup 1, no. 2 (2019): 121-137.

${ }^{23}$ Yuhananik, "Kajian Teologis Konsep Kebahagiaan Menurut Matius 5:3," Jurnal Teologi Berita Hidup 1, no. 2 (2019): 138-153.
} 
kunjungan kepada orang sakit atau pelayanan penghiburan. Bahkan sekalipun suatu pelayanan sudah memiliki jadwal, tidak menutup kemungkinan ada hal-hal insidental yang memerlukan penggantian pelayan Tuhan, misalnya pelayan yang terjadwal melayani mendadak sakit. Dalam hal ini pelayan Tuhan lain yang melayani dalam bidang yang sama perlu siap sedia dalam segala keadaan.

Rasul Paulus berpesan kepada Timotius, bahwa Timotius sebagai pemberita firman harus siap sedia memberitakan firman Tuhan dalam segala keadaan (2Tim. 4:2). Jika pelayan Tuhan hanya mau melayani pada saat keadaan baik, maka pelayanannya banyak digagalkan oleh keadaan. Tuhan tidak menjanjikan kehidupan Kristen terbebas dari masalah, bahkan Rasul Paulus memberikan kesaksian tentang berbagai masalah yang dialaminya dalam pelayanan. Keadaan tidak baik yang sedang dialami oleh pelayan Tuhan seharusnya tidak menjadi alasan untuk mengundurkan diri dari pelayanan.

\section{Dapat menjaga rahasia}

Gereja adalah persekutuan orang-orang percaya, namun tidak berarti orang-orang percaya yang ada dalam persekutuan tersebut adalah orang-orang yang sudah dewasa secara rohani. Kadang-kadang ditemukan adanya warga jemaat yang belum mampu mencerna sebuah informasi sehingga menafsirkan informasi tersebut secara keliru. Semakin seorang warga jemaat terlibat dalam pelayanan, semakin banyak informasi yang diterimanya. Sebagaimana seorang huperetes yang banyak menerima informasi seputar kegiatan tuannya. Informasi yang diterima oleh seorang pelayan Tuhan dapat menjadi masalah ketika diteruskan dan diterima oleh orang yang tidak tepat. Itu sebabnya seorang pelayan Tuhan perlu belajar untuk memilah-milah, mana informasi yang perlu diteruskan, dan mana informasi yang perlu disimpan dulu sebagai rahasia.

Membocorkan rahasia berarti mengkhianati kepercayaan yang telah diberikan seseorang. Sengaja atau tidak sengaja, ada dampak yang merusak dari kegagalan menyimpan rahasia. Dalam kitab Amsal dituliskan, mulut yang mengucapkan apa yang tidak perlu bisa membinasakan sesama (Ams. 11:9) bahkan meruntuhkan kota (Ams. 11:10). Ketidakmampuan seorang pelayan Tuhan dalam menyimpan rahasia juga menunjukkan bahwa ia tidak bisa mengendalikan diri..

\section{Memiliki kepedulian pada sesama}

Karya keselamatan yang dikerjakan Allah bukan hanya memulihkan hubungan manusia dengan Allah, tetapi juga hubungan manusia dengan sesamanya. Oleh sebab itu pelayanan kepada Tuhan tidak dapat mengabaikan pelayanan kepada sesama. Orang tidak bisa berkata bahwa ia mengasihi Allah tanpa menunjukkan bahwa ia juga mengasihi sesamanya. Karena mustahil seseorang dapat mengasihi Allah yang tidak kelihatan kalau ia tidak mengasihi sesama yang kelihatan. Itu sebabnya seorang pelayan Tuhan harus bisa menunjukkan kepedulian kepada sesama. 


\section{Setia dan bertanggung jawab kepada rumah Tuhan}

Seorang pelayan Tuhan bisa saja tidak setia kepada bidang pelayanannya karena tergoda untuk beralih kepada bidang pelayanan lain. Memang tidak menutup kemungkinan ada orang-orang yang memiliki multitalenta sehingga ia dapat melayani Tuhan di banyak bidang. Dibutuhkan kesetiaan dari seorang pelayan Tuhan untuk menekuni bidang pelayanan yang dipercayakan kepadanya.

\section{Memiliki integritas}

Kehidupan seorang pelayan Tuhan dilihat oleh banyak orang, karena sesuai artinya seorang leitourgos berdiri di depan banyak orang untuk melayani mereka. Ia dikelilingi banyak saksi. Ada potensi kemunafikan pada seorang pelayan Tuhan, saat di hadapan banyak orang ia tampil sebagai pribadi yang tanpa cacat tetapi di tempat lain yang tidak terlihat ada dosa yang disembunyikan. Itu sebabnya seorang pelayan Tuhan harus hidup dalam integritas.

Integritas berarti keterpaduan, kebulatan, keutuhan; juga berarti jujur dan dapat dipercaya. ${ }^{24}$ Pelayan Tuhan yang berintegritas memiliki keutuhan dan keselarasan dalam pikiran, perasaan, sikap perbuatan dan perkataan. Tidak ada rekayasa atau kepalsuan, karena semua aspek di dalam dirinya sinkron dan harmonis. Menurut Anggu, pada pelayan yang berintegritas tidak didapati suatu noda yang mengurangi harga diri dan wibawanya. ${ }^{25}$ Sebaliknya pelayan Tuhan yang ingin dipuji orang bisa terjebak pada pencitraan, sehingga tidak sinkron lagi aspek internal dan eksternalnya, artinya ia kehilangan integritas.

Karena berkaitan dengan keberadaannya di hadapan banyak orang, maka sebelum seseorang ditetapkan sebagai pelayan Tuhan, ia perlu terlebih dulu diuji integritasnya. Paulus memberi nasihat kepada Timotius agar calon pelayan Tuhan (dalam hal ini seorang diaken) diuji dulu, setelah ternyata tak bercacat barulah ditetapkan dalam pelayanan (1Tim. 3:10).

\section{Mempersiapkan diri untuk pelayanan}

Kadang-kadang dengan alasan bahwa Tuhan melihat hati, maka ada pelayan Tuhan yang melayani jemaat Tuhan tanpa performa yang baik, misalnya seorang pemimpin pujian bernyanyi dengan suara yang sumbang. Hal ini tentunya tidak sesuai dengan arti leitourgos yang mengharuskan tampil dengan performa yang baik di hadapan orangorang. Itu sebabnya pelayan Tuhan perlu melakukan persiapan yang baik. Berbagai bentuk pelatihan perlu dijalani oleh pelayan Tuhan yang melayani pada bidang-bidang tertentu ini. Seorang pengkhotbah perlu dipersiapkan melalui serangkaian studi Alkitab dan cara berkhotbah; seorang pemimpin pujian perlu dipersiapkan melalui pelatihan

\footnotetext{
${ }^{24}$ Kamus Besar Bahasa Indonesia, 5th ed. (Badan Pengembangan Bahasa dan Perbukuan, Kementerian Pendidikan dan Kebudayaan Republik Indonesia, 2019).

${ }^{25}$ Peter Anggu, "Integritas Diri Sebagai Karakter Seorang Pelayan Tuhan," Jurnal Jaffray 3, no. 1 (2005): 56-60.
} 
vokal yang baik. Bahkan seorang penyambut jemaat pun perlu dipersiapkan untuk memberikan penyambutan yang terbaik kepada warga jemaat yang hadir.

Persiapan dalam melayani bukan hanya dilakukan ketika seseorang akan dilantik sebagai pelayan Tuhan. Persiapan perlu tetap dilakukan setiap kali akan melayani. Dengan demikian pelayan Tuhan akan mempersembahkan yang terbaik bagi Tuhan melalui pelayanannya. Persiapan rutin dalam bentuk pelatihan akan meningkatkan kapasitas pelayan Tuhan. Seorang pelayan Tuhan berada dalam keadaan berbahaya ketika ia merasa mapan dan puas dengan tahap pengalamannya. Rasa mapan dan berpuas diri kadang-kadang membuat orang tidak lagi berlatih untuk memperbesar kapasitas. Tidak ada ukuran kuantitatif untuk kapasitas seseorang, tetapi penilaian apakah seseorang dikatakan berkapasitas dapat dilakukan oleh orang-orang yang ada di sekitar, seperti keluarga, tempat kerja atau lingkungan pelayanan di gereja. Seorang pelayan Tuhan yang tidak memperbesar kapasitas akan dirasakan oleh orang-orang di sekitarnya bahwa telah terjadi stagnasi di dalam pelayanannya.

\section{Aplikasi}

Setelah pembahasan tentang arti kata pelayan, maka nampaknya perlu bagi gereja Tuhan pada masa kini menetapkan kriteria-kriteria bagi warga jemaat yang akan dilantik sebagai pelayan. Karena ada beragam bidang pelayanan, ada kemungkinan kriteria yang ditetapkan tidak bisa sama untuk seluruh pelayan Tuhan, contohnya kriteria yang ditetapkan untuk pelayan mimbar mungkin berbeda dengan yang ditetapkan untuk penyambut jemaat. Hal ini adalah wajar, karena Paulus pun menetapkan kriteria yang berbeda untuk penilik jemaat dan diakon (1Tim. 3).

Bila gereja menetapkan standar minimal bagi warga jemaat untuk menjadi pelayan Tuhan, diharapkan dapat dicegah adanya pelayan Tuhan yang hidupnya menjadi sandungan sehingga pelayanannya tidak menjadi berkat. Namun demikian, kriteria yang ditetapkan gereja juga tidak boleh menjadi penghalang bagi seseorang untuk terlibat pelayanan; gereja perlu menyadari bahwa tidak ada manusia yang sempurna, jangan sampai ketidaksempurnaan justru menghalangi seseorang melayani Tuhan.

\section{Kesimpulan}

Melalui studi kata dapat disimpulkan bahwa seorang pelayan Tuhan adalah warga gereja yang memiliki karakteristik sebagai berikut: Pelayan Tuhan adalah seorang hamba Kristus, yang sadar bahwa hidupnya adalah milik Kristus karena Kristus sudah menebus hidupnya. Ia berkomitmen kepada satu tuan, yaitu Kristus. Ia memiliki ketaatan penuh dan kerendahan hati. Ia segera memberikan respons berupa tindakan dan bukan hanya berbicara tentang tugas yang dipercayakan kepadanya. Ia tidak tidak perlu mencari hormat bagi diri sendiri. Ia harus siap sedia dalam segala keadaan. Ia harus dapat menjaga rahasia. Ia selalu memperhatikan orang lain dalam memenuhi kebutuhannya. Ia memiliki kesetiaan dan tanggung jawab kepada rumah Tuhan. Ia memiliki kehidupan yang diamati banyak orang, karenanya ia harus hidup dalam integritas. Ia mempersiapkan diri agar dapat melayani ibadah dengan baik. 


\section{Referensi}

Anggu, Peter. "Integritas Diri Sebagai Karakter Seorang Pelayan Tuhan.” Jurnal Jaffray 3, no. 1 (2005): 56-60.

Baker, Joy Don. "The Purpose, Process, and Methods of Writing a Literature Review." AORN Journal 103, no. 3 (2016): 265-269.

Balz, Horst Robert, and Gerhard Schneider. Exegetical Dictionary of the New

Testament. Grand Rapids, MI: Eerdmans, 1993.

Damazio, Frank. The Making of A Leader. Portland: City Bible Publishing, 1988.

Gerhard Kittel, Geoffrey William Bromiley, and Gerhard Friedrich. Theological Dictionary of the New Testament. Grand Rapids, MI: Eerdmans, 1976.

Jokiman, Bob. "Dasar-Dasar Alkitabiah Pengembangan Kepemimpinan." Veritas : Jurnal Teologi dan Pelayanan 4, no. 1 (2018): 87-106.

Juld, Rahel Jum, and I Ketut Enoh. “Okultisme Dalam Pelayanan Pastoral.” Jurnal Jaffray 11, no. 2 (2013): 165.

Kusnandar, Yotam Teddy. "Pentingnya Golden Character." Epigraphe 1, no. 1 (2017): $11-22$.

Magnan, Sally Sieloff, and John W. Creswell. "Research Design: Qualitative and Quantitative Approaches." The Modern Language Journal 81, no. 2 (2006): 256.

Napitupulu, Ferry. "Uang Terima Kasih Dipatok Pendeta," Kompasiana, Desember 23, 2011, https://www.kompasiana.com/silversteven/550ble28813311e8a8/uangterima-kasih-dipatok-pendeta

Pigai, Ferry. "Analisis Ciri Kepemimpinan Hamba Serta Relevansinya Pada Masa Kini Berdasarkan Injil Matius 20:26-28 [Analysis of the Characteristics of Servant Leadership and Relevance Based on the Gospel of Matthew 20:26-28]." Jurnal Jaffray (2013).

Santo, Joseph Christ. "Makna Dan Penerapan Frasa Mata Hati Yang Diterangi Dalam Efesus 1: 18-19." Jurnal Teologi Berita Hidup 1, no. 2 (2018).

Setiawan, Jimmy. "Menggagas Signifikansi Gestur Tubuh Dalam Ibadah Korporat Gereja Gereja Protestan [Initiating the Significance of Body Gesture in Corporate Protestant Church Worship]." Veritas 13, no. 1 (2012): 99-120. http://repository.seabs.ac.id/handle/123456789/264.

Sumiwi, Asih Rachmani Endang. "Pembaharuan Pikiran Pengikut Kristus Menurut Roma 12:2." Jurnal Teologi Berita Hidup 1, no. 1 (2018).

Swanson, James. Dictionary of Biblical Languages With Semantic Domains : Greek (New Testament). Edited by Inc. Logos Research Systems. Oak Harbor, 1997.

Wijaya, Yahya. "Kepemimpinan Yesus Sebagai Acuan Bagi Kepemimpinan Gereja Masa Kini.” Jurnal Jaffray 16, no. 2 (2018): 129.

Yonathan, Danny. "Memahami Konsep Menyangkal Diri, Memikul Salib Dan Mengikut Yesus: Sebuah Analisis Biblikal Lukas 9:23-26.” Jurnal Teologi Berita Hidup 1, no. 2 (2019): 121-137.

Yuhananik. "Kajian Teologis Konsep Kebahagiaan Menurut Matius 5:3.” Jurnal Teologi Berita Hidup 1, no. 2 (2019): 138-153.

Zaluchu, Sonny. "Analisis Kisah Para Rasul 15 Tentang Konflik Paulus Dan Barnabas Serta Kaitannya Dengan Perpecahan Gereja.” Kurios 4, no. 2 (2018): 107-117. http://www.sttpb.ac.id/e-journal/index.php/kurios.

Zaluchu, Sonny. "Respons Tests of Leadership Menurut Teori Frank Damazio Pada Mahasiswa Pascasarjana Jurusan Kepemimpinan Kristen STT Harvest Semarang." Jurnal Jaffray 16, no. 2 (2018): 145-160. https://ojs.sttjaffray.ac.id/index.php/JJV71/article/view/289.

Kamus Besar Bahasa Indonesia. 5th ed. Badan Pengembangan Bahasa dan Perbukuan, Kementerian Pendidikan dan Kebudayaan Republik Indonesia, 2019. 